\title{
Development of 72A High Carbon Wire Rod for Bead Wire
}

\author{
Cao Shuwei \\ Production Management Department \\ Anyang Iron \& Steel Group Co., Ltd. \\ Anyang 455004, Henan, China \\ Caoshuwei2007@163.com
}

\begin{abstract}
High carbon steel wire rod $72 \mathrm{~A}$ is an important raw material for manufacturing steel wire-rope, bead wire and hose steel wire. Based on strict chemical composition design, reasonable adjustment and optimization of smelting and continuous casting, reheating, rolling as well as cooling processes etc., Anyang Iron And Steel Group Co., Ltd. produced successfully the $\Phi 6.5 \mathrm{~mm}$ of high carbon steel wire rod grade 72A at its 100t Converter-High Speed Wire Rod Mill. The results showed that the production process of trial steel was reasonable with narrow range of chemical composition, low centerline segregation and good mechanical performance. The deviation range of tensile strength of wire rod for same heat, same nominal diameter and same rolling system is less than $50 \mathrm{MPa}$, the sorbite of metallographic structure reached more than $88 \%$. All performance can meet the requirements of the bead wire.
\end{abstract}

Keywords-high carbon steel wire rod; production process; composition control; centerline segregation; microstructure; mechanical property

\section{INTRODUCTION}

The product drawn from high carbon steel wire rod is one of the main materials for manufacture of bead wire, hose wire and steel cord of radial tire. In recent years, the output of steel wire rod and steel wire has been in an upward trend both in developed and developing countries. With the development of Chinese automobile industry, the demand on bead wire is increasing year by year [1]. The high carbon steel wire rod with high quality is an important raw material for the manufacture of steel wire rope, pre-stressed steel wire, bead wire, spring wire and steel cord, etc. which is a high value-added product and has a broad market. High carbon steel wire rod grade 72A is mainly used for manufacturing cold drawing or cold rolling products as well as the framework material of rubber products such as tire, conveyer belt and high pressure hose. The steel wire must has the excellent comprehensive mechanical properties of high strength, good toughness, antifatigue and impact resistance, and it is the high strength steel wire rod for deep processing of wire drawing [2]. Anyang Iron and Steel Group Co., Ltd., as a main steel wire rod manufacturer in China, has the advantages of large-scaled and modernized equipment, the process control of which can completely satisfy the needs of the development of high grade steel wire rod. For exploring the domestic and overseas markets, increasing the market competitiveness, improving the product quality, promoting the product upgrade and realizing the superior- product strategy, the $\mathrm{R} \& \mathrm{D}$ and trial production of prime high carbon steel wire rod grade 72A was carried on in Anyang Iron and Steel Group Co., Ltd.

\section{PRODUCTION PROCESS}

\section{A. Process flow}

72A high carbon steel wire rod adopts the following production process:

BF hot metal $\rightarrow 100$ t convertor smelting $\rightarrow$ LF secondary refining $\rightarrow 150 \mathrm{~mm} \times 150 \mathrm{~mm}$ billet continuous casting $\rightarrow$ walking beam furnace reheating $\rightarrow$ high pressure water descaling $\rightarrow$ high speed wire rod rolling $\rightarrow$ laying $\rightarrow$ Stelmor cooling $\rightarrow$ reform tub $\rightarrow \mathrm{P} / \mathrm{F}$ line conveying $\rightarrow$ finishing, testing $\rightarrow$ packing $\rightarrow$ warehousing.

\section{B. Composition design}

High carbon steel wire rod grade 72A are mainly used for manufacturing bead wire and other deep drawing products, whose technical quality requires stricter than that of normal high carbon pre-stressed wire. It requires narrow range of chemical composition, small centerline segregation, and pure steel and low content of hazard elements. On the basis of current process equipment of Anyang Iron and Steel Co. Ltd., the chemical composition design of trial steel is given as in Table 1.

TABLE I. CHEMICAL COMPOSITION, /WT \%

\begin{tabular}{llllllll}
\hline $\mathrm{C}$ & $\mathrm{Si}$ & $\mathrm{Mn}$ & $\mathrm{P} \leqslant$ & $\mathrm{S} \leqslant$ & $\begin{array}{c}\mathrm{Cr} \\
\leqslant\end{array}$ & $\begin{array}{c}\mathrm{Ni} \\
\leqslant\end{array}$ & $\begin{array}{c}\mathrm{Cu} \\
\leqslant\end{array}$ \\
\hline $0.70 \sim 0.74$ & $0.15 \sim 0.30$ & $0.40 \sim 0.60$ & 0.025 & 0.020 & 0.10 & 0.10 & 0.10 \\
\hline
\end{tabular}

\section{Steelmaking process}

\section{1) Smelting process}

The catch carbon smelting process was adopted. In process of smelting, the key point is to control C, Mn and Si of steel into a narrow range, and control lower content of $\mathrm{P}, \mathrm{S}$ and residual elements in steel. To reduce the content of residual elements, the high quality scrap or self-produced scrap is used, the tapping temperature was designed to be more than $1600^{\circ} \mathrm{C}$. Top-slag such as Lime and fluorite were charged when tapping. 
Mn-Si alloy and a small amount of Fe-Si were preferably used for pre-deoxidation and alloying. Calcium carbide and silicon carbide were used for end-deoxidation. Secondary slagstopping was taken and slag carrying over is strictly prohibited for nose and tapping hole. The LF refining time is not less than 50 minutes, the white slag holding time is minimum 15 minutes, and the weak stirring time is minimum 10 minutes.

\section{2) Continuous casting process}

The quality of continuous casting billet has a big effect on the property of final product. The inner core area of billet should be dense (loose and shrink hole should be small), the centerline segregation of billet should be small [3]. Especially for manufacturing high quality steel wire, centerline segregation and composition fluctuation will cause performance non-uniformity of wire rod and cause wire broken easily. For getting good mechanical properties and drawing performance, superheat of liquid steel and casting speed was tightly controlled for minimum centerline segregation [4].The centerline segregation of 72A wire rod of Anyang Iron and Steel Group Co., Ltd. is required less than level 3. To obtain the good solidification of billet, the full protection was used for continuous casting to guarantee Ar sealing of long nozzle. The long nozzle sealing gasket was used for good sealing of submerged nozzle to ensure the submerged nozzle centerline in mould. Mould electromagnetic stirring was used and double layers of casting powder were charged in tundish, of which the lower layer is neutral covering agent, and the upper layer is carbonated rice husk. It was controlled to a low target overheat and steady casting speed.

\section{Steel rolling process}

\section{1) Reheating process}

Reheating furnace is side-in and side-out walking beam type. The rated heating capacity is $120 \mathrm{t} / \mathrm{h}$, and $140 \mathrm{t} / \mathrm{h}$ max. From the charging side to discharging side, along the length direction, the furnace are divided into preheating, heating and soaking sections with lengths of $6250 \mathrm{~mm}, 7750 \mathrm{~mm}$ and $6700 \mathrm{~mm}$ respectively. For adjusting flexibly the temperature of each section and adapting the heating needs of easy decarburized steel, the screwdown structure was installed at the top of soaking section and heating section. The key combustion device is imported from Japan. The control system network is 2-level structures with total of 6 automatic temperature control sections, which can realize the calculation and control of optimized combustion digital model and guarantee the heating quality of billet. The device has the characteristics of flexible production operation, good heating quality and low heating cost.

In order to reduce oxidation loss and decarbonization of high carbon steel billet in reheating furnace, the heating temperature and time must be controlled strictly. Heating temperature was controlled below $1100^{\circ} \mathrm{C}$ and heating time was less than 150min [5]. To avoid de-carbonization of high carbon steel, the reheating temperature was controlled in lower limit values by reheating zone of $950{ }^{\circ} \mathrm{C} \sim 1000{ }^{\circ} \mathrm{C}$ and soaking zone of $1050{ }^{\circ} \mathrm{C} \sim 1080{ }^{\circ} \mathrm{C}$, thus guarantee $960{ }^{\circ} \mathrm{C} \sim 1000{ }^{\circ} \mathrm{C}$ of start rolling temperature.

\section{2) Controlled rolling process}

The production line adopts fully continuous non-twisted arrangement with 30 rolling stands. The mill is consist of 5 groups that are 6 roughing stands, 8 intermediate rolling stands, 4 pre-finishing stands, 8 finishing stands and 4 reducing/sizing stands. Cooling water tanks are arranged behind pre-finishing stand, finishing stand and reducing/sizing stand, which ensures the accurate temperature control to rolled piece during rolling.

High precision geometry, uniform rod size, and smooth and non-defect surface are the development characteristics of high speed steel wire rod and the requirements of excellent drawing performance [6]. The mill uses the latest patented technology "8+4" of Morgan company, that is adding 4 reducing/sizing stands after cooling section of finishing stand. This process has the following advantages.

a) It can realize precise rolling and ensure dimensional accuracy of $\pm 0.10 \mathrm{~mm}$ for all the sizes of product.

b) It can simplify pass system. All the sizes of product can be rolled by the reducing/sizing stand, thus roller change is reduced, and the operating rate is improved.

c) It can realize free rolling of certain sizes, increase product specifications. For example, the groove for the production of $\Phi 6$. $0 \mathrm{~mm}$ wire rod can also produce that of $\Phi 5.75 \mathrm{~mm}$ and $\Phi 6.25 \mathrm{~mm}$, which meets the special requirement of customer for different sizes of wire.

d) It can reduce the rapid temperature rising due to deformation of rolled piece in high speed area, and realize the temperature controlled rolling of low temperature high speed, thus ensure the metallurgical quality of the product, especially for the high quality high carbon wire rod.

3) Controlled cooling process

The mill adopts Stelmor conveyer with “Optiflex” plenums of large air volume, high air pressure and retarded cooling device developed by Morgan. The length of bulk cooling conveying line is $103.8 \mathrm{~m}$. The conveyer cover is $81 \mathrm{~m}$ long, conveying speed is $0.1-2 \mathrm{~m} / \mathrm{s}$, and the cooling speed is $0.3-20^{\circ} \mathrm{C}$ /s. It has 14 centrifugal cooling fans with air volume of $154000 \mathrm{~m}^{3} / \mathrm{h}$ each and air pressure of $3.0 \mathrm{kPa}$. The air pipe is equipped with "Optiflex" electric air flow distributor. The Stelmor conveying line can deliver the mutually overlapping laying coil to collecting station from laying head, take forced cooling and retarded cooling to wire rod for obtaining the best metallographic structure and mechanical property.

For most of the steel grades, heat treatment process can be completed on-line to improve the metallurgical quality and uniform performance of products. Especially for steel cord, bead wire and pre-stressed wire, this effect is more prominent, the obtained performance can close to the index of lead bath quenching, and can reduce the diameter of $\Phi 5.5 \mathrm{~mm}$ wire to $\Phi 1.2 \mathrm{~mm}$ within one drawing pass, also can control scale forming, This not only omits the heat treatment before drawing, but also reduces the difficulty of surface cleaning for the next process, get the products of excellent quality in all respects. This can bring the obvious economic and social benefits in work rate increase and cost reduction for wire deep processing customers. 
High carbon steel wire rods require higher tensile strength. Unlike strengthening and toughening mechanism of low carbon steel, the strengthening mechanism of high carbon steel is to improve the strength of product mainly by getting sorbite structure. For obtaining higher sorbite content, the super-cooled austenite phase transformation is needed to occur in lower temperature zone. To accomplish this, it must improve the stability of super-cooled austenite on the one hand, and raise the post-rolling cooling temperature to increase subcooling and decrease the temperature of super-cooled austenite changing to pearlite on the other hand. Structure of hot rolled steel wire rod grade $72 \mathrm{~A}$ is to be sorbite plus pearlite plus small amount of ferrite, martensite is not permitted. Sorbite ratio must be more than $80 \%$, and average grain size should be above level 7 .

\section{TTIAL RESULT}

\section{A. Composition control}

To ensure the smooth drawing and stranding, it requires the uniform and stable chemical composition, low content of hazardous element. The actual composition of trial steel 72A was given in Table 2. It can be seen that the fluctuation of composition is small, and especially the carbon control is very strict.

TABLE II. CHEMICAL COMPOSITIONS OF THE TRIAL STEEL /WT \%

\begin{tabular}{ccccccccc}
\hline Item & $\mathrm{C}$ & $\mathrm{Si}$ & $\mathrm{Mn}$ & $\mathrm{P}$ & $\mathrm{S}$ & $\mathrm{Cr}$ & $\mathrm{Ni}$ & $\mathrm{Cu}$ \\
\hline Maximum & 0.73 & 0.23 & 0.53 & 0.014 & 0.006 & 0.03 & 0.012 & 0.02 \\
Minimum & 0.71 & 0.21 & 0.51 & 0.011 & 0.002 & 0.02 & 0.008 & 0.01 \\
\hline
\end{tabular}

\section{B. The control of centerline segregation}

The centerline segregation of high carbon steel is one of the important factors that cause wire broken when drawing to bead wire. Too high segregation degree will bring adverse effects on structure control in rolling process, and make the non-uniform distribution of inclusion in steel, easily to cause wire broken. The centerline segregation of high carbon steel is mainly generated by columnar crystal, and the casting temperature is the important factor to affect crystal growth [7]. During the trial production, when strictly controlled the superheat of liquid steel and casting speed, weak secondary cooling, and the centerline segregation was improved obviously. The centerline segregation of wire rod is less than level 2; see Fig. 1 and Fig. 2.

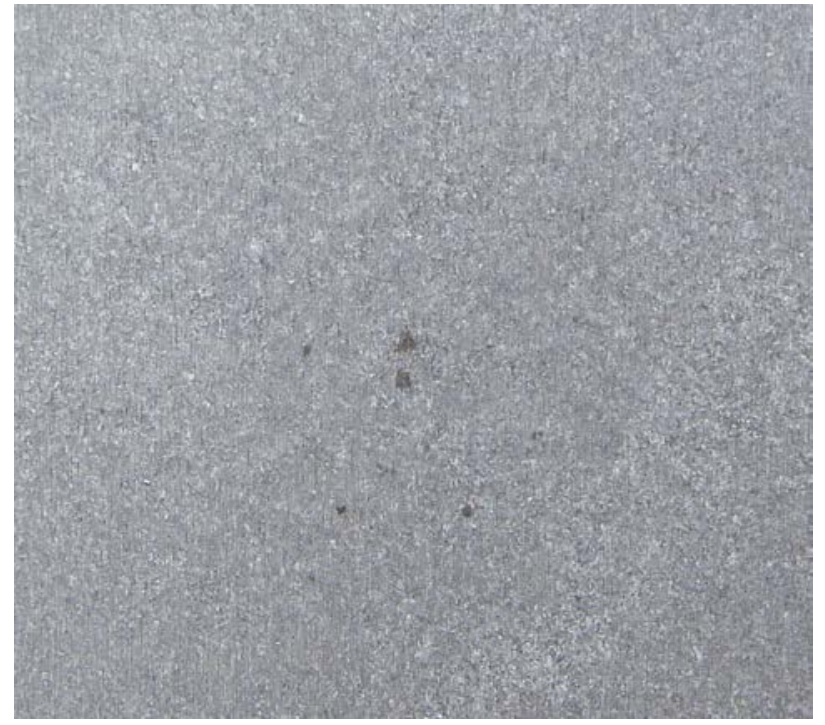

Fig. 1. Macrostructure of steel billet

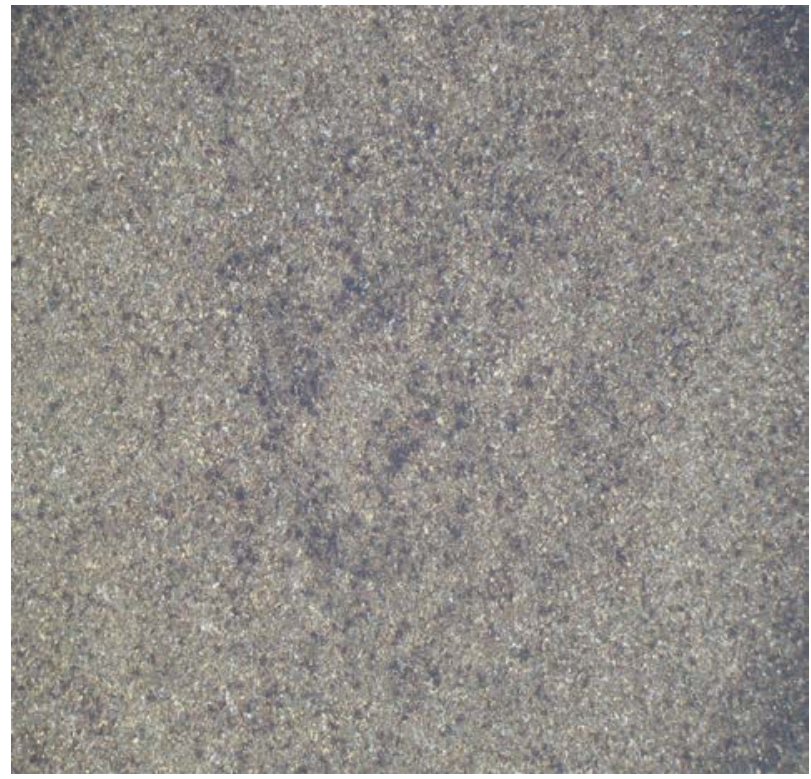

Fig. 2. Macrostructure of wire rod section

\section{The structure control of wire rod}

The structure of trial material is sorbite (the main)+ pearlite + ferrite after controlled rolling and controlled cooling, please see Fig. 3. After hot rolling, the proportion of sorbite reaches 88 93\% (area fraction) in the matrix, the higher content of sorbite structure ensures the good mechanical property and drawing performance of hot rolled wire rod. 


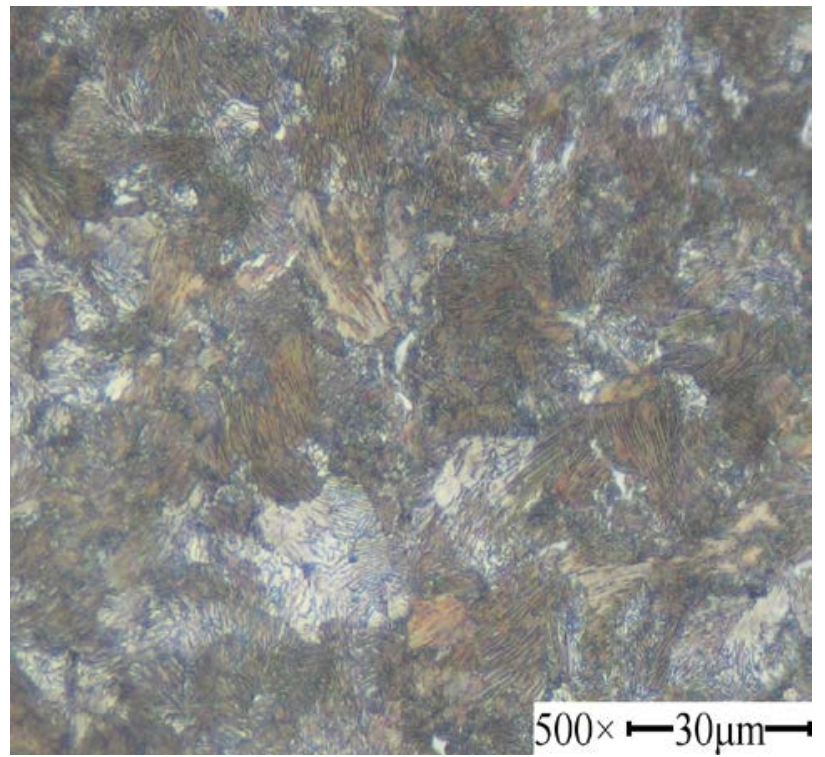

Fig. 3. Microstructure of 72A wire rod

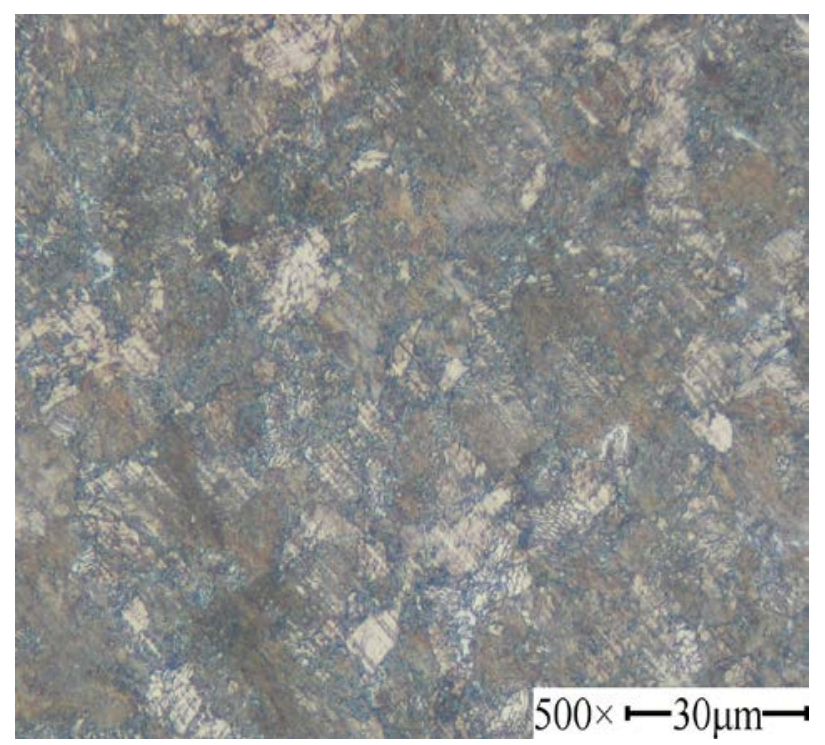

Fig. 4. Microstructure of $72 \mathrm{~A}$ wire rod

\section{Mechanical property control of wire rod}

The reasonable controlled rolling and controlled cooling process makes the high proportion of sorbite in metallurgical structure of wire rod, thus obtained the ideal mechanical property. The mechanical property is given in Table 3.

TABLE III. MECHANICAL PROPERTIES OF TESTED 72A WIRE ROD

\begin{tabular}{cccc}
\hline Item & $\begin{array}{c}\text { Tensile } \\
\text { strength Rm, } \\
\text { MPa }\end{array}$ & Elongation A, \% & $\begin{array}{c}\text { Reduction of } \\
\text { area Z, \% }\end{array}$ \\
\hline Maximum & 1070 & 22 & 59 \\
Minimum & 1020 & 16 & 46 \\
Average & 1050 & 18 & 52 \\
\hline
\end{tabular}

It can be seen from the table 3, when all of the trial steel rolled to the wire rod of $\Phi 6.5 \mathrm{~mm}$, the fluctuation range of its tensile strength is less than 50MPa, which fully reaches the requirement that the fluctuation range of the tensile strength of wire rod with same furnace number, same nominal diameter, and same rolling schedule is not more than $170 \mathrm{MPa}$ specified as per the relevant standard of the state.

\section{APPLICATION OF WIRE ROD}

This batch of $\Phi 6.5 \mathrm{~mm}$ of hot rolled wire rod grade $72 \mathrm{~A}$ for bead wire, produced by Anyang Iron and Steel Group Co., Ltd., was supplied to a well-known domestic bead wire enterprise of China for test use. Its production process of wire drawing is: wire rod $\rightarrow$ inspection $\rightarrow$ paying-of $\rightarrow$ mechanical descaling $\rightarrow$ steam blowing $\rightarrow$ cold water rinsing $\rightarrow$ electrolytic pickling $\rightarrow$ borax $\rightarrow$ drying $\rightarrow$ rough drawing $\rightarrow$ lead bath heat treatment $\rightarrow$ fine drawing $\rightarrow$ tempering, copper plating $\rightarrow$ water rinsing $\rightarrow$ surface treatment $\rightarrow$ coating $\rightarrow$ drying $\rightarrow$ taking up. Practice showed shat all performance data of hot rolled wire rods 72A for bead wire, produced by Anyang Iron and Steel Group Co., Ltd., can meet the requirement of bead wire industry.

\section{CONCLUSION}

High carbon steel wire rod grade 72A for bead wire, developed by Anyang Iron and Steel Group Co., Ltd., and has the narrow control range of chemical composition, pure steel and lower hazardous element content. The process control of continuous casting is reasonable, the superheat control of liquid steel is strict; the casting speed is stable; the centerline segregation of billet is lighter; and the centerline segregation of wire rod is less than level 2. Through application by users it showed that the wire rod has the good surface quality, less decarburization, high proportion of sorbite structure, good uniformity of mechanical performance, suitable strength and better use effect. It can completely meet the requirement of users, and lay the foundation for Anyang Iron and Steel Group Co., Ltd. to develop new grade of wire rod for steel cord.

\section{REFERENCES}

[1] Song Qinghua, Wang Bojian, and Liu Shifeng, Production Present Situation of Bead Wire, Steel Wire Product, vol. 32, pp. 12-13, August 2006. (In Chinese)

[2] Cao Shuwei, Sun Rulin, Zhao Xianping. Control and Analysis of Quality Influencing Factors of High Carbon Wire Rod C72DA, China Metallurgy, vol. 20, pp. 36-40, October 2010. (In Chinese)

[3] Cai Kaike, Sun Yanhui, Qin Zhe. Controlling on the Quality of Special Steel Billet Produced by BOF-LF-CCM Process, Steelmaking, vol. 24, pp. 1-6, June 2008. (In Chinese)

[4] CAO Shu-wei, WANG Xin-jiang, KANG Yong-lin. Development and Application of C72DA Wire Rod for High-pressure Hose[J]. Steel Rolling, 2010,27(4) :65-67. (In Chinese)

[5] CAO Shu-wei, KANG Yong-lin, WANG Xin-jiang. Development of LX70 Wire Rod for Steel Cord[J].Iron and Steel, 2011,46(9) :74-77. (In Chinese)

[6] Qiao Deyong, Li Manyun. Production of High Speed Wire Rod Mill, Metallurgical Industry Press, Bijing, 1999, pp. 390-392. (In Chinese)

[7] Wang Yong. Li Benhai, Xu Xiaodong. Research and Development of LX72A Wire Rod for Tyre Cord, China Metallurgy, vol. 15, pp. 37-41, August 2005. (In Chinese) 